\title{
Communicating the Social Sciences
}

\section{Angela Cassidy}

This chapter reviews the sparse and somewhat scattered research literature that has specifically addressed the public communication of the social sciences (PCSS). This literature, in common with much research on the public communication of science and technology (PCST), lacks consistency or indeed clear definitions of what is meant by 'social science', 'natural science' and indeed, 'science'. Analyses of social science media coverage indicate that the social sciences are communicated in some quite different patterns from those seen with natural science research. Some authors have suggested that this may be due to the overlap between the subject matter of social science research (people), and experiential, 'common sense' knowledge. Other relevant literature, on 'self-help' psychology books, public intellectuals, and social scientists as expert witnesses.

There is an urgent need for more consistent, systematic research addressing PCSS, in order to understand better the general issues involved in communicating expertise and those faced specifically by the social sciences. Researchers in PCST should reflect on these issues in order to address reflexively how we communicate publicly about our field, just as we seek to advise other researchers on how best to communicate in the public domain.

\section{A partial view of sciences}

As the other contributions to this volume attest, research and practice in many aspects of PCST has grown hugely in recent years. Despite this growth, relatively little attention has been paid to the specific issues that social scientists are faced with when communicating about their research in the public domain. In the published literature 'science communication' is usually taken to mean the physical, chemical, biological and occasionally medical or engineering sciences, and work on PCSS has been relatively sparse and scattered across several disciplinary areas. In part, this may be because the historical impetus for science communication and public understanding of science has mostly come from natural science. However, the more recent critique of traditional 'deficit model' approaches to science communication has come from social scientists. In this light, it is curious that such researchers have not applied this critique to their own disciplines of sociology, history, anthropology and communication studies and rarely, if ever, conduct research studies of PCSS. In most countries, mass media have specifically targeted output for covering 'science' in one form or another, such as TV and radio programmes about science, science sections in newspapers and popular science books. Science journalism is a well recognised and respected journalistic specialism, and such professionals provide content for both specialist science and mainstream media output. The majority of this coverage tends to be of the above mentioned natural science disciplines, although social sciences such as psychology do receive some specialist attention. Particularly in the English-speaking media, there is little or 
no corresponding specialisation in the social sciences, which, as I will explore here, has profound implications for the kind of coverage they receive.

The weakness of research in PCSS and of specialisation in social sciences among media professionals is all the more striking when we consider that social science research is extensively covered in the broader, non-specialist media. Crime figures, census data, educational research, economic analysis, psychology and political theory are all examples of social science which contribute to the central, day to day content of modern media. Events promoting public discussion of science, such as the annual meeting of the British Association for the Advancement of Science frequently feature a good deal of social science, showing it can play a prominent role in science communication at times. The much discussed role of the 'public intellectual' is often taken on by social scientists, particularly in the USA and continental Europe. Social research forms the core activity of many think-tanks, active by definition in the public domain. Social researchers frequently act as expert witnesses in court, and offer policy, personal and lifestyle advice to all and sundry. In the UK, in particular, social scientists have been instrumental in the development of PCST as a research field, and in initiating widespread change in the policy and practice of both governmental and scientific institutions. It is with all this in mind that I review what is currently known about PCSS, and ask the associated question of why social scientists, particularly those in PCST, have paid so little attention to the popular discussion of their own work.

\section{Literature on PCSS}

Research and writing about social science communication is highly disparate and exists in a number of unrelated areas, but when brought together, this work provides interesting insights into what happens to social science in the public domain. There are quantitative and qualitative analyses of media content; interview-based studies; analytical work; and material written by social scientists or professional associations addressing the promotion of social science in the public domain, including 'how to' guides for academics. Of these, the last is the most commonplace, recalling in many ways the PCST literature fifteen or twenty years ago. As with much PCST research, the literature is dominated by studies based in the USA and UK, and this bias has important implications for our understanding of social science communication. In English-speaking countries, relatively strong distinctions are drawn between natural science (studies of the natural world) and social science (studies of the human and social) research. This is often associated with a 'hierarchy of the sciences', which places physics at the top, life sciences a little lower, social science below that, and arts/humanities subjects as often outside 'science' altogether. Furthermore, popular ideas about the nature of science reinforce the status of subjects which use quantitative, experimental or statistical methods. In continental Europe and elsewhere in the world, such distinctions are less starkly drawn, and conceptions of science tend to include all forms of scholarly research in their remit, as conceptualised in the German term wissenschaft. Due to this anglocentric bias, as well my own language constraints, the conclusions drawn in this piece must apply largely to English-speaking countries. Where possible, I have 
referred to studies from the rest of the world, but considering the paucity of the literature as a whole, much more research is needed to reach any coherent understanding of the effect of these cross-cultural differences upon the public communication of the social sciences.

Much of the available literature on PCSS is by psychologists; material coming from other disciplines, or addressing social science as a whole, is far less common. This is probably indicative of psychology's borderline status between the natural and social sciences, where the increased use of quantitative, experimental approaches boosts its 'scientific' status, making it more likely to be covered by journalists (Schmierbach, 2005). The greater prominence of psychology may also be reflective of psychologists' greater concern with their own public image compared to other social sciences, a concern shared with natural sciences, and seen in the more extensive and longstanding use of media relations by psychological associations and events. Subject area notwithstanding, a great deal of PCSS literature is written by social researchers drawing on their own communication experiences, and frequently resembles older PCST literature in the emphasis on how to get the 'correct' message across in the media (e.g. Haslam \& Bryman, 1994; Kirschner \& Kirschner, 1997). The public image problems of social science are discussed, and strategies to improve the situation often centre upon upbraiding journalists for sensationalism, inaccuracy, and lack of understanding of the social science research process (Goldstein, 1986; McCall and Stocking, 1982). In recent years, professional associations and funding bodies have paid greater attention to improving the skills of researchers when engaging with the media (Gaber, 2005; ESRC, 1993; 2005). However, the overriding concern remains with the promotion of the social sciences, rather than a more reflective engagement with the issues at hand.

A second area of literature, in places closely related to the above, consists of content-analysis studies of social science media coverage. Weiss and Singer (1988) carried out an extensive study of the American news media during the 1980s, comprising parallel content analysis and interview studies. Key findings included the discovery that the majority of coverage was framed as stories 'about' the subject of the research (for example crime or parenting), with the research itself appearing as ancillary references. Furthermore, only seven per cent of the stories found were written by specialist science journalists, with most coverage authored by generalists, or specialists in other areas. The coverage was analysed by content theme rather than subject area, but it is still plain from this that economics commanded the largest share of social science coverage in the USA media. A similar approach, using a broader sweep of methods, was taken in researching the UK situation in the following decade (Fenton, et al., 1997; 1998) and this study reveals an interesting pattern of similarities and differences between the USA and UK. As in the USA, social science was not covered by science journalists in the UK: in fact only one such example was found in the entire sample studied. Instead, named journalists writing on specific issues produced the majority of the coverage, with the rest specialists in other areas. In contrast to the US study, social issues provided the largest proportion of the coverage, with economic issues coming a distant second, and 
psychology was the most frequently represented discipline. Fenton et al (1997; 1998) report that research did provide the main focus of most stories in the UK, rather than ancillary mentions. Most of the social science coverage analysed appeared as features rather than news articles, and social scientists more often appeared reactively as commentators and advisers on specific issues according to the news agenda, rather than being the principal source of stories.

Both of these studies also looked at how much, and where, media coverage of social science appeared, and again transatlantic differences emerge. In the USA, coverage was distributed evenly across all forms of media, and levels of reporting found were far higher than in the UK, where coverage was heavily concentrated in the broadsheet (or 'quality') press. However, without meaningful comparisons, it is difficult to draw useful conclusions from these figures: are they high or low, and in what terms? Similarly, it is difficult to distinguish whether many of the issues raised by these studies are specific to the social sciences, or are broader concerns shared in the public communication of all research. A study by Evans (1995) deals with this problem by directly comparing US media coverage of social and natural science research. The study found that of the total sample of research coverage, 36 per cent was of social science subjects, although this is not broken down into disciplinary groupings. The Science Museum Media Monitor (Bauer et al, 1995), one of the largest studies of its kind, took a continental European definition of 'science' as inclusive of the social sciences, and reported a gradual increase in the proportion of social science coverage over the second half of the twentieth century, eventually reaching similar levels to that found by Evans. A smaller study carried out by Hansen and Dickinson (1992) found only 15 per cent of coverage was of social sciences, but related fields such as market research, 'human interest' and science policy/education were separated out from this, leading to a combined figure of 28 per cent. Overall, these studies suggest that the social sciences provide a substantial proportion of media coverage of research in both the US and UK, overtaken only by health and biomedicine. By contrast, studies on coverage of the social sciences in the German media have found that they are relatively underrepresented (e.g. Böhme-Durr, 1992).

Evans (1995) made some interesting comparisons which chime strongly with the findings of qualitative research addressing PCSS issues, discussed below. For example, social science was much less likely to appear in newspaper science sections than natural science, and more likely to be in general news coverage, confirming the idea that science journalists rarely cover the social sciences. In interviews Dunwoody (1986), found that US science journalists typically look down on social science research as less 'scientific', express little interest in it, and regard it as requiring little specialist training to report. Evans (op cit.) also found that social scientists were accorded a lower epistemological status in media reports, being less often referred to as 'researchers' or 'scientists' and more frequently in terms such as 'the authors of the study'. Finally, he notes the lack of specific 'source' academic journals for media coverage of social science research, compared to major natural science sources such as Nature and Science. In m study of UK press coverage of 
evolutionary psychology, (Cassidy, 2005) I also found that, compared with evolutionary biology, evolutionary psychology was covered less often by science journalists, more by non-specialists, appeared more frequently in features and commentary pieces, and rarely in specialist science coverage. Fenton et al's (1997, 1998) research also investigated relationships between social science and the media, this time in the UK; they note that social science is not usually covered by correspondents with any in-depth knowledge of research, that it is rarely newsworthy in its own right, and instead is covered as part of changing broader news agendas. Furthermore, they describe the relationship between academics and the media in this area as 'formal, distant and highly reliant on the role of facilitators' (Fenton et al, 1998; $p$ 70). Thirty per cent of the researchers they interviewed had worked with the media only via communications professionals, a pattern reflected in interactions between researchers and journalists at academic conferences (ibid.).

\section{Status of social science}

Contrary to what might be expected, social science faces many institutional barriers in public communication which are less of a problem for natural science, mostly relating to the relative lack of status accorded to social research in the public domain, and traditional hierarchies of science that place physics and mathematics at their apex, and messier, 'subjective' subjects such as sociology and anthropology lower down. Although many social scientists may have abandoned such notions, they remain powerful in popular culture, and have a strong effect on journalistic practice and cultural attitudes. Divisions of labour between science journalists (often trained in natural science) and other journalists (who often have a non-research background, for example in humanities) may well serve to reinforce such notions (Schmierbach, 2005). As described above, Anglo-American definitions of 'science' which exclude the social sciences (particularly qualitative research) may accentuate these effects. However, research conducted in Germany suggests that they are more universal: science journalists there also judged social science disciplines negatively, and in general social science in the media was less prestigious than natural science (Böhme-Durr, 1992; see also Wessler, 1995).

Although the social sciences may not always enjoy the same status in the media as the natural sciences, it may be that social scientists play a different, and at times more influential role, as experts in the wider public domain. A Norwegian study (Kyvik, 2005) found that in that country academics in the humanities and social sciences were more publicly active (in terms of writing popular articles and media contributions such as availability for interview) than their colleagues in natural science, medical and technical subjects. This is also suggested by the small body of work on popular and self-help psychology, which is also largely US-based, unsurprising considering the origins and importance of the genre in that country. Many of these studies take a discursive approach, addressing, for example, the regulation of heterosexuality in John Gray's Mars and Venus series of books on relationships between men and women (Potts, 1998); or masculinity in popular books on child development (Anderson and Accomado, 2002). The rhetorical 
language of pop psychology has been examined, showing how ideas about self-help tie into discourses of individuality and personal growth, are closely related to New Age movements (Askehave, 2004), as well as the broader values of modern liberal democracies (Hazleden, 2003). Considering the obvious popularity of these texts as seen through the vast sales figures they secure not only in the USA but globally, this work gives an insight into an arena where social science is highly influential on ordinary people's lives. Crawford (2004) takes this further by investigating audience responses to the Mars and Venus series, by analysing a television programme showing couples discussing the book Men are from Mars, Women are from Venus (1992). Crawford argues that this shows how audiences' responses to these books rarely consist of straightforward absorption and that instead people can use such texts to open up a space for negotiating and challenging the claims made therein.

Another relevant literature is that surrounding the idea of the 'public intellectual' - broadly understood as a person of learning, not necessarily an academic, who uses their knowledge to engage in wider society through debating in the public domain (Small, 2002). Although this idea is hardly new, academic and popular discussions of 'the public intellectual' have burgeoned in the past few years. However, this has been a conversation strongly centred on humanities/social science and has barely featured in the literature on PCST issues. Although many people thought of as public intellectuals such as the late Edward Said (1994), have been writers and thinkers in the humanities, many others are and have been social scientists. A survey about public intellectuals, carried out by the UK political magazine Prospect in 2005, put a social scientist (Noam Chomsky) at the top of its list of 100 public intellectuals, and many other social scientists featured prominently (Prospect, 2005). Therefore, the literature on public intellectuals is of interest to anyone concerned with PCSS. A key debate in this literature turns upon the 'duty' of public intellectuals to be politically engaged in society, and how they should best carry this out (Alcoff, 2002). In a similar vein, the sociologist Michael Burawoy (2005) has called for 'public sociology', arguing that this is a role which should be taken on more by his colleagues. This has sparked debates about the role of sociology in the public domain and whether it should be politically engaged at all (Clawson et al, 2007). A recent paper on this has touched upon the potential risks and pitfalls of engaging with the media, describing a specific case, how the research message was changed by media reporting, and the lack of media awareness of the authors (Grauerholtz and Baker-Sperry, 2007). This suggests that both areas could benefit from some cross-talk: while recent PCST research has had much to say about academic engagement with the media, broader issues of expertise, politics and the public domain have received less attention (but see chapter 9 in this volume).

\section{The case of psychology}

Psychoanalysis is also an important area for understanding the popular influences of social science, particularly in terms of the above literature on self-help books. Serge Moscovici's (1961) classic study of popular psychoanalysis provides an unusually historical and European view of PCSS issues, addressing as it does three 
different parts of French society during the 1950s. Moscovici argued that each milieu carried a slightly different 'social representation' of psychoanalytic ideas, each of which reflected its own values and ideas. More recently, Park (2004) has compared the contemporary discourses of popular psychiatrists with those of psychoanalysts, arguing that the two groups strategically position themselves against each other, respectively as medical, 'scientific' experts, and as broader intellectual authorities. He relates these opposing, yet complementary strategies to the differing forms of public intellectual visible in contemporary popular culture. Unlike the popular scientist, the public intellectual comments on a broad range of issues rather than keeping to their own area of expertise. It could be argued that natural scientists such as Richard Dawkins and Stephen Jay Gould have taken on such a role. This may signal an increasing source of 'competition' for social scientists' expertise in the public domain, as natural science research on subjects such as genetics and neuroscience comments increasingly on traditionally 'social science' research topics.

Research on UK media coverage of the newly emerging subject of evolutionary psychology has also investigated these tensions, as evolutionary psychology is located on the boundaries between the natural and social sciences. Most evolutionary psychologists work within positivist, naturalistic and quantitative traditions of social science, such as cognitive psychology. Through a series of popular books, public lectures, media interviews and articles, they argued in favour of using evolutionary theory and quantitative, experimental methods to research human behaviour, society and culture. At the same time, these popular arguments attacked opposing theories and methods for understanding 'human nature', such as the interpretive research traditions of sociology and anthropology, and cultural explanations of human behaviour. This popular coverage helped evolutionary psychologists to reach audiences across disciplinary boundaries, and move the subject from a relatively marginalised position to one of establishment in academia (Cassidy, 2005; 2006). It also stimulated a public debate in the UK media, involving psychologists, philosophers, biologists, feminists, novelists, commentators and journalists. This keyed into other issues under debate at the time, including heterosexual relationships, feminism and gender, centre-left politics, and the prominence and role of bioscience (such as genetics, evolution and neurobiology) in understanding and governing society (Cassidy, 2007). This research also picked out a key issue for understanding PCSS - the overlap between the expert knowledge of social science researchers and people's everyday experience of human existence. Participation in EP debates was not restricted to accredited 'experts' in the subject, but instead included a much wider range of people. Like much social science, it was rarely covered as 'science' in the media, and 'lay' forms of knowledge such as personal experience, common sense and gender identity were often drawn upon to make arguments both for and against EP (Cassidy, 2004).

Paying attention to the subject matter of social science research is central to understanding how it is communicated and understood in the public domain. Because the social sciences investigate the realm of the human - people, their minds, societies, money, politics, and so on - the subjects, researchers, communicators and 
audiences of research tend to bleed into one another. Unlike the natural sciences, where expertise is almost by definition held by researchers and specialists, social scientists' expertise is often about matters of everyday experience and commonsense knowledge, impacting on how highly that expertise is regarded. For example, Evans (1995) reports that US journalists made strong demarcations between natural science and social science, between natural science and lay opinion, but not between social science and lay opinion. As psychologists McCall and Stocking (1982; p988) put it:

Everyone, including journalists and editors, fancies himself or herself something of a psychologist, but not an astrophysicist. Results from psychology, but not physics, must therefore square with experience to be credible.

Fenton et al. (1998) also found that news media audiences do precisely this in framing their understandings of social science research findings. They also found that the consequent overlap between the professional role of the social scientist and that of the journalist resulted in further under-reporting of social research, as journalists often felt it was little different from their own work, and therefore not inherently newsworthy. Similar issues of the 'scientific' legitimacy of social science expertise have also been seen in studies of social scientists' role as expert witnesses. Legal definitions of 'science' in the USA are heavily traditional, positivist ones, leading at times to non-natural science expertise being judged as inadmissible (Lynch and Cole, 2005).

However, these overlaps between social science, journalism and everyday knowledge also have positive implications for PCSS. Historian of psychology Graham Richards (2002) has described this phenomenon as 'reflexive science', while Fenton et al (1998; 102) refer to it as 'epistemological consonance'. Media 'news values' which often result in natural science struggling to gain media coverage can often work in favour of the social sciences. Examples of such news values include relevance (to daily life), consonance (with existing beliefs), topicality, controversy, and of course human/personal interest (Weiss and Singer, 1988: 144-9; Fenton, et al., 1998: 103-13; Gregory and Miller, 1998: 110-4). In this light, it becomes less surprising that the content analyses discussed earlier showed social science to be a very widely reported area of research. Epistemological consonance can also help explain media attitudes that journalists do not require specialist training to report social science, ironically also increasing the chances of social science research being reported in the first place. As described above, generalists tend not to have training in either natural or social science, and neither do editors, ironically increasing the chances that social science will make it through the editorial process. Furthermore, social scientists can and have used the overlap between their research and everyday knowledge to help popularise their work, emphasising the commonality or the separation between the two areas, according to their rhetorical purposes (Derksen, 1997, 2000; Shapin, 2001). 


\section{Concluding remarks}

Although the literature on PCSS is sparse and scattered across many disciplinary areas, some interesting trends have emerged, alongside striking gaps in the literature and opportunities for further research, many pertaining specifically to the social sciences. A close examination of social science communication also opens up some crucial questions for the broader field of PCST research. With so little work done, it is difficult to reach firm conclusions about social science communication, and so any assertions made here are by necessity highly provisional and subject to further investigation. Despite this, one thing is immediately clear: social science is simultaneously marginalised and immensely popular in the public domain, at least in the English speaking world. Social science research has a lower epistemological status than natural science, is less likely to be newsworthy in and of itself, does not merit media or journalistic specialisation, and at times is seen as little different from journalism itself. Much of this stems from the social sciences' marginal status on the boundaries of 'science', both in mass media and wider society. At the same time, social science is very frequently covered by the media, seen as relevant to audiences, easy to understand, and appears throughout media coverage rather than being confined to an area of special interest, as with natural science. As such, social scientists often have important roles to play as commentators and advisers on social, political and personal issues.

Beyond these rather broad-brush assertions, it is difficult at this stage to draw any more nuanced conclusions about social science communication. The criteria used for coding content-analysis studies have been so variable that it is very difficult to draw meaningful comparisons between them. They have been carried out in different countries, sometimes decades apart, over different timescales, coding for different data and using variable definitions of social science and indeed 'science', which is also a problem for PCST research in general. Therefore the most urgent need is for further work, preferably using a comparative approach, to look at the communication of a broad spread of disciplines, including social sciences. In the studies reviewed here, some intriguing suggestions of cross-cultural differences have emerged, particularly in the popularity of particular disciplines, and of the social sciences as a whole. However, little work has been done outside of an AngloAmerican context, and so further studies, particularly in continental Europe and in the rest of the world, are also urgently needed. Similarly, little attention has been paid in PCST research to the role of historical context and change on the public communication of the social sciences. This is notwithstanding the forty year time period under study in the Bauer et al (1995) study of the British press, and a thriving literature addressing histories of popular (natural) science (Cantor and Shuttleworth, 2004).

Although much research attention has been paid to the work of specialist science journalists, the widespread reporting of social science by non-specialists highlights the fact that little or no work has been done on how generalist journalists 
understand and report academic research. The reflexive nature of social science, and the idea that this is what makes PCSS so different from PCST, is one that also requires further investigation. This is particularly as it may also cast light on what makes communicating natural science so difficult at times, particularly in those subjects very far from human experience. Furthermore, it may provide an important contribution to current debates about the construction of expertise (Collins and Evans, 2002) and the related issues of public engagement with science and scientific decision making (Leach et al, 2005). Understanding how and why PCSS is different from PCST would also be helpful for practitioners, as communicating the complex findings of social science, particularly those of qualitative research, presents a significant challenge. As noted above, social scientists have until recently paid far less attention to the public and communicative aspects of their work than their colleagues in the natural sciences. Considering that social science research is far more likely to be of relevance and importance to public debates, media reporting and indeed the majority of ordinary people, there has been a curious lack of attention amongst social researchers to these issues.

As a final note, I would like to present a challenge to researchers and practitioners working in PCST: how do we communicate about our work on communication, and publicly engage about public engagement? Surely, if we aim to advise natural scientists, policymakers and politicians about these issues, then we should 'practice what we preach' and communicate openly and ably ourselves. However, the extra levels of reflexivity introduced in PCST work ('communicating about research which is about communicating about research') is unlikely to be compatible with media news values, for example. Surely one of the most urgent challenges facing our field is to start looking for the answers to such questions; both through further research work, and by providing practical examples of engaging in the public domain about the importance of PCST research.

\section{Suggested further reading}

Crawford, M. (2004) 'Mars and Venus Collide: A Discursive Analysis of Marital SelfHelp Psychology' Feminism and Psychology, 14: 63-79.

Evans, W. (1995) 'The mundane and the arcane: Prestige Media Coverage of Social and Natural Science' Journalism and Mass Communication Quarterly, 72: 168-177.

Fenton, N., Bryman, A., Deacon, D. and Birmingham, P. (1998) Mediating Social Science. London: Sage.

Lynch, M. and Cole, S. (2005) 'Science and Technology Studies on Trial: Dilemmas of Expertise' Social Studies of Science, 35: 269-311.

Small, E (2002) (ed.) The Public Intellectual. London: Blackwell.

Weiss, C.H. and Singer, E. (1988) Reporting of Social Science in the National Media. New York: Russell Sage Foundation. 


\section{Other References}

Alcoff, L.M. (2002) 'Does the Public Intellectual Have Intellectual Integrity?' Metaphilosophy, 33: 521-534.

Anderson, K.J. and Accomando, C. (2002) "Real' Boys? Manufacturing Masculinity and Erasing Privilege in Popular Books on Raising Boys' Feminism and Psychology, 12(4): 491-516.

Askehave, I. (2004) 'If language is a game - these are the rules: a search into the rhetoric of the spiritual self-help book If Life is a Game - These are the Rules' Discourse and Society, 15(1): 5-31.

Bauer, M., Durant, J., Ragnarsdottir, A. and Rudolfsdottir, A. (1995) Science and Technology in the British Press 1946-1990: A Systematic Content Analysis of the Press (vols. I-IV). London: Science Museum.

Böhme-Durr, K. (1992) 'Social and Natural Sciences in German Periodicals' Communications: The European Journal of Communication Research, 17(2): 167-76.

Burawoy, M. (2005) '2004 Presidential Address: For Public Sociology' American Sociological Review, 70(February): 4-28.

Cantor, G. and Shuttleworth, S. (eds.) (2004) Science Serialised: Representations of the Sciences in Nineteenth Century Periodicals. Cambridge, MA: MIT Press.

Cassidy, A. (2004) Of Academics, Publishers and Journalists: Evolutionary Psychology in the UK Media. PhD. thesis, Edinburgh: University of Edinburgh

--- (2005) 'Popular evolutionary psychology in the UK: an unusual case of science in the media?' Public Understanding of Science, 14, 115-141.

--- (2006) 'Evolutionary Psychology as Public Science and Boundary Work' Public Understanding of Science, 15(2): 175-205.

--- (2007) 'The (Sexual) Politics of Evolution: Popular controversy in the late twentieth century UK' History of Psychology, 10(2): 199-227.

Collins, HM and Evans, R (2002) 'The Third Wave of Science Studies: Studies of Expertise and Experience' Social Studies of Science, 32(2): 235-296.

Clawson, D. Zussman, R., Misra, J., Gerstel, N., Stokes, R., Anderton, D. and Burawoy, M. (2007) Public Sociology: Fifteen Eminent Sociologists Debate Politics and the Profession in the Twenty-first Century. Berkeley, CA: University of California Press.

Crawford, M. (2004) 'Mars and Venus Collide: A Discursive Analysis of Marital SelfHelp Psychology' Feminism and Psychology, 14: 63-79.

Derkson, M. (1997) 'Are We Not Experimenting Then? The Rhetorical Demarcation of Psychology and Common Sense' Theory and Psychology 7(4): 435-456

--- (2000) 'Boundaries and commonplaces: The rhetorical demarcation of common sense' Paper given at Demarcation Socialised: Millennial, Quinquennial Workshop at Cardiff University, August 2000.

Dunwoody, S. (1986) 'The Science Writing Inner Club: A Communication Link Between Science and the Lay Public' In: Friedman, SL, Dunwoody, S and Rogers, CL (eds.) Scientists and Journalists: Reporting Science as News. New York: Macmillan.

Evans, W. (1995) 'The mundane and the arcane: Prestige Media Coverage of Social and Natural Science' Journalism and Mass Communication Quarterly, 72: 168-177. ESRC (1993) Pressing Home Your Findings: Media Guidelines for ESRC Researchers. Swindon: UK Economic and Social Research Council. 
--- (2005) Communications Toolkit. Swindon: UK Economic and Social Research Council. http://www.esrc.ac.uk/ESRCInfoCentre/Support/Communications\%5FToolkit/

Fenton, N., Bryman, A., Deacon, D. and Birmingham, P. (1997) "'Sod off and find us a boffin": journalists and the social science research process' Sociological Review, 45(1): 1-23.

Fenton, N., Bryman, A., Deacon, D. and Birmingham, P. (1998) Mediating Social Science. London: Sage.

Gaber, A. (2005) 'Media Coverage of Sociology' Sociological Research Online, 10(3) www.socresonline.org.uk/10/3/gaber.html.

Goldstein, JH (ed.) (1986) Reporting Science: The Case of Aggression. Hillsdale, NJ: Lawrence Erlbaum Associates.

Grauerholtz, L. and Baker-Sperry, L. (2007) 'Feminist research in the public domain: Risks and Recommendations' Gender and Society, 21(2): 272-294.

Gray, J. (1992) Men are from Mars, Women are from Venus: A Practical Guide for Improving Communication and Getting What You Want in Your Relationships. New York: HarperCollins.

Gregory, J. and Miller, S. (1998) Science in Public: Communication, Culture and Credibility. New York: Plenum Trade.

Hansen, A. and Dickenson, R. (1992) 'Science coverage in the British mass media: media output and source input' Communications, 17(3): 365-77.

Haslam, C. and Bryman, A. (1994) Social Scientists Meet the Media. London: Routledge.

Hazleden, R. (2003) 'Love yourself: The relationship of the self with itself in popular self-help texts' Journal of Sociology, 39(4): 413-428.

Kirschner, S. and Kirschner, D.A. (1997) Perspectives on Psychology and the Media. Washington, DC: American Psychological Association.

Kyvik, S. (2005) 'Popular science publishing and contributions to public discourse among university faculty' Communications, 26, 2885-311.

Leach, M, Scoones, I and Wynne, B (2005) Science and Citizens: Globalisation and the challenge of engagement. London: Zed Books.

Lynch, M. and Cole, S. (2005) 'Science and Technology Studies on Trial: Dilemmas of Expertise' Social Studies of Science, 35: 269-311.

McCall, R.S. and Stocking, S.H. (1982) 'Between scientists and public: communicating psychological research in the mass media' American Psychologist, 37: 985-95.

Moscovici, S. (1961) La Psychanalyse: Son Image et son public. Paris: Presses Universitaires de France.

Park, D.W. (2004) 'The Couch and the Clinic: The cultural authority of popular psychiatry and psychoanalysis' Cultural Studies, 18(1): 109-133.

Potts, A. (1998) 'The Science/Fiction of Sex: John Gray's Mars and Venus in the Bedroom' Sexualities, 1(2): 153-173.

Richards, G. (2002) Putting Psychology in its Place: A Critical Historical Overview $\left(2^{\text {nd }}\right.$ edition). London: Routledge.

Said, E.W. (1994) Representations of the Intellectual: the 1993 Reith Lectures. London: Vintage 
Schmierbach, M. (2005) 'Method Matters: The Influence of Methodology on Journalists' Assessments of Social Science Research' Science Communication, 26(3): 269-287.

Shapin, S. (2001) 'Proverbial Economies: how an understanding of some linguistic and social features of common sense can throw some light on more prestigious bodies of knowledge' Social Studies of Science, 31(5): 731-769

Small, E (2002) (ed.) The Public Intellectual. London: Blackwell.

Weiss, C.H. and Singer, E. (1988) Reporting of Social Science in the National Media. New York: Russell Sage Foundation.

Wessler, H. (1995): Die journalistische Verwendung sozialwissenschaftlichen Wissens und ihre Bedeutung für gesellschaftliche Diskurse [The journalistic use of socialscientific knowledge and its relevance for social discourses]. Publizistik, 40: 20-38 